\title{
Big data: perspectives of using in urban planning and management
}

\author{
Nikolay Ivanov ${ }^{1, *}$ and Maxim Gnevanov ${ }^{1}$ \\ ${ }^{1}$ Moscow State University of Civil Engineering; 26, Yaroslavskoe Shosse, Moscow, 129337, Russia
}

\begin{abstract}
To date, there is no doubt about the need and possibilities of using large amounts of information. So called "Big Data" technology is used in a variety of areas, and urban planning is no exception. The article discusses how to use large amounts of information for a competent design of social and engineering urban networks in the interests of cities residents while preserving historical appearance of cities. The proposed hypothesis states that urban planning can transition to a new higher level with the introduction of "Big Data" technology based on the concept of "Smart City", which not only makes the life of residents comfortable, but also allows making timely adjustments to one or other urban process with the purpose of its improvement. Additionally, possible approaches of the concept implementation and their applicability under various conditions are discussed. The article analyzes the experience of Smart City concept implementation as a part of "Big Data" technologies in practice of a number of European cities. Important positive results of such implementation are noted. The role and place of each of the parties interested in sustainable development of the city, in the development of intellectual systems for managing this development is discussed. In particular, a lot of attention is paid to the role of the state as the initiator and coordinator of interaction between the parties, the main holder and user of data, services and infrastructure. It is concluded that the potential built into the "Big Data" technology will allow us to move to a new level of urban planning, based on real urban data collected by various technical means.
\end{abstract}

\section{Introduction}

In the last 5-10 years, the amount of information that is accumulated in the world which concerns various spheres of our life has increased significantly. Therefore, by defining the correct ways of processing huge amounts of information, it is possible to predict a particular event with a high probability and to correct its activities in order to get the maximum result. Serova K. in defines that "Big Data" (BDAT) are arrays of information, ways of their processing and sphere of application [1].

BDT finds application in various spheres, including in urban planning [2]. The city is a complex system of various connections, such as spatial, pedestrian, transport. Their

\footnotetext{
* Corresponding author: IvanovNA@mgsu.ru
} 
identification is facilitated by the flow of data generated by residents: mobile phone signals, credit card transactions, messages on social networks that are in the public domain. According to Serova K., by means of such data it is possible to see the city in an absolutely new perspective and to carry out an assessment of problems in traffic and cultural identity of urban areas [1].

Modern urban planners need an understanding of what BDT technologies are, how they can be used, how the results of their application can be visualized. As noted by Davletkaliyev R. in [3], the movement of people in urban space is often a chaotic movement, but in fact somewhere in the virtual space they all have a very close relationship, and it can provide serious assistance in the process of building social and engineering infrastructure of the city, while respecting the interests of residents.

\section{Methodology}

Today, the city is undergoing a global transformation. Development requires the creation of an infrastructure based on intelligent networks. Technologies should serve as a basis for the development of new cities and be integrated into existing ones. These tasks can be solved through the introduction of BDT technology based on the concept of an integrated approach Smart city.

The concept of Smart city is intended to use intellectual and information communication technologies for the management of urban property. The main objective of the considered concept - to meet the needs of residents of the city. Volynskov points out that Smart City technology is able to cover almost all areas of urban planning and management, including the architectural component, public administration, transport and communal systems, public safety, financial structures, Commerce, production, as well as the creation of a residential environment [4].

An important element of the concept is intellectual innovation, which is based on information technology and data analysis. Their spread has an impact on the economic landscape, creating new fast-growing areas or making radical changes to existing ones. At the same time, the data of the innovation generation process can come through two channels: from automated accounting systems fixing various parameters of urban systems to residents creating formalized requests for changes.

Today, the concept of Smart City is actively developing in the United States, developed countries in Europe and Southeast Asia. The experience of these countries allows us to identify two main approaches to the implementation of the concept.

The first approach is based on the introduction of Smart city technologies through the design and creation of new cities. Thanks to the use of this technology, the infrastructure of future cities is carefully thought out. In addition, maximum integration of all urban systems is ensured. Examples of this approach include planned or ongoing projects of cities in countries such as South Korea, UAE, China [4].

Most often, the technology is implemented on the territory of small, compact settlements, where the infrastructure is initially created in accordance with pre-developed, often quite stringent standards [5]. Usually the development of such a city, according to Volynskov [4], is considered as a single mega-project, detailed into individual projects and sub-projects, and the evaluation of its effectiveness is carried out from the standpoint of economic effects.

The second, more common approach is the implementation of the "smart city" concept in already existing cities where local or complex projects are implemented on the basis of the existing infrastructure in the framework of the introduction of intelligent technologies, then integrated into systems. This approach is highly relevant when implementing it on the territory of ancient cities, as it is intended, along with the modernization of the city, to 
preserve the monuments of architecture and the appearance of old cities. Through the use of information - communication infrastructure and technology, it is possible to adapt urban systems to existing needs and pressures, thereby reducing costs by reducing resource consumption, improving the quality of services and creating new points of economic growth.

Smart City technologies are increasingly included in the daily life of citizens, as these technologies are provided to improve the efficiency of urban services. These technologies also act as a centralized means of obtaining services on energy and water supply, urban infrastructure, transport, etc.

\section{Results}

Today, all countries of the world are experiencing a boom in information. According to experts, over the past $10-15$ years, more than $90 \%$ of all data on the planet has been created: it concerns information about Internet users posted by them through social networks and other services, data from mobile operators and GPS, information from outdoor surveillance cameras in the streets, data from various sensors from cars (private cars, taxi cars, etc.) [6].

Through gradual digitization of all spheres of life, a person begins to understand that these "digital traces" include an understanding of how life works, if I may say so, "from a bird's eye view." Accordingly, if you find the right ways to process large amounts of information, it is likely to carry out a prediction of an event and carry out a correction of its activities to get the maximum result everywhere - from advertising campaigns that sell a particular type of product, to predictions of urban traffic or natural disasters.

Modern urban planners cannot exist without an understanding of the nature and structure of BDT, the technology of their use or the ability to visualize them. Planning of social and engineering infrastructure of the city should be based on the analysis of virtual information of its residents in order to meet their interests.

Rob Kitschin - professor of the National University of Ireland has been conducting research on cities for more than twenty years as part of the Programmable city project. To date, the researcher takes part in two major projects, the cost of each of which is several million euros. One of them was initiated by the European research Council. The project analyses the social, political and economic impacts of smart cities. The second project is continuing work on the Dublin Dashboard project. "Dublin Dashboard" is an open data site that combines official statistics about the city, as well as interactive maps about all aspects of Dublin's life. Prof. Kitchin is scaling this project for the whole country on the order of the Science Foundation of Ireland.

BDT technologies are also used in solving transport problems. An example is London, which introduced the use of a universal electronic map for public transport ("Oyster Card"). By analyzing data on the movement of residents, it is possible to obtain information on the direction and extent of their movements on such modes of transport as buses, trams, trains, and, if necessary, to make changes in the routes and schedules of transport. This technology solves another problem: transportation on different types of transport is carried out by different providers, and if it is necessary to change any route, a single instrument of influence on them is needed.

Experience of introducing the Smart city concept into the practice of European cities within the BDT technology shows that the result of such implementation is an increase in the overall level of safety, including environmental safety, reduction of emissions and consumption of resources. The authors in [8] noted that with the use of intellectual technologies in London, energy consumption decreased by $30 \%$, street crime decreased by $30 \%$, traffic - by $20 \%$, water losses decreased by $20 \%$. As for the indirect effects achieved as a result of better management decisions and the development of a better urban 
environment, it is necessary to note the noticeable growth of economic and social activity of the population, the positive dynamics of the main economic indicators, the increase in income of the population and the volume of budget funds.

An effective prerequisite for the development of Smart city technologies lies in the organization of large-scale international events that require ideal operation of transport, security systems and management. All of the above can be implemented in the concept of "Smart city". "Smart city" urban planning concept of integrating multiple information and communication technologies (ICT) and Internet for the management of municipal property; the assets of the city include, but are not limited to, local information systems departments, schools, libraries, transportation, hospitals, power plants, water and waste management systems, law enforcement and other public services [9].

The purpose of the above-mentioned concept is to improve the quality of life through the technology of informatization of the urban environment to improve the efficiency of service and meet the needs of residents. Methodological recommendations for the development of national reports on human settlements development of the CIS countries for the UN world conference on human settlements [10] regulate that the structure of the concept of "Smart city" is presented as an organization of cooperative systems requiring openness and standardization, the absence of which will lead to a cumbersome and expensive project. Its main difference from ordinary cities is the tactics of relations with citizens, which consists in a special focus on the person, based on the ICT infrastructure and the constant development of the city [11]. As a consequence of the increase in the population, there is an increase in pressure on the cities, which leads to the need to organize an ecological and energy-efficient life in them.

The following components are included in the unified integration platform for Smart city concept implementation:

1. Transport: the possibility of photo and video fixation (FVF), weight control (VGK), parking space, electronic ticket, automated traffic management system (ASUDD.

2. Housing and communal services: implementation of the "Bright City" system; use of IT systems for utilities.

3. Security: introduction of video surveillance systems, threat monitoring, coordination and interaction systems, eco-monitoring.

4. Tourism: development of a tourist map, introduction of public Wi-Fi [12].

\section{Discussion}

International experience shows that the main customer of the Smart city concept development is the authorities, which ensure the formation of long-term vision and an integrated approach in the introduction of technologies [13]. The state can be an independent customer of new technologies and solutions, create incentives for business to implement the necessary technologies. An important aspect of the implementation of the concept is a clear understanding by the authorities of the goals and expected results.

Development and implementation of intelligent systems should be accompanied by the involvement of all parties interested in sustainable development of the city (residents of cities, local communities, public and non-profit organizations, professional associations, representatives of large, small and medium-sized businesses). Hollis L. V [14] points out that the state should act as a coordinator of such interactions, ensuring the identification of the views and interests of all these parties, as well as opening access to the process of management and use of data, services and infrastructure.

\section{Conclusions}


The government, business, society, and most importantly the professional community of architects and urban planners today has a unique opportunity to influence the life and structure of cities, using such a tool as BDT, and implementing it with the help of Smart city technologies [15]. But for the full realization of this possibility, it is necessary to solve a number of problems. First, changes in the regulatory framework are needed: a standard is needed that regulates the use and application of BDT by the professional community. Secondly, there is a problem of the need to organize joint activities of planners, urban planners, urbanists in the process of data collection and processing. Third, you need to learn how to work with BDT and use them correctly. It is necessary to develop methods for the use of BDT in urban planning. They should be based on different types of data and methods of data processing and be used for different urban development tasks: zoning, security, improvement of transport and pedestrian traffic.

Big Data technologies should play an important role in urban planning, as they have considerable potential to bridge the gap between the conceptual understanding of cities and urban real data collected by various technical means.

\section{References}

1. K. Serova, Big Data for large cities (2018) http://habidatum.com/project/easy-accessrussian-cities/

2. A. Konikov, G. Konikov, IOP Conf. Ser.: Earth Environ. Sci. 90, 012184 (2017) DOI:10.1088/1755-1315/90/1/012184

3. R. Davletkaliev, What is Big Data. Part 2 (2018) https://habrahabr.ru/post/308586/

4. V.E. Volynskov, Academia. Architecture and Construction, 2, pp. 29-32, (2017)

5. E.V. Nezhnikova, Economics of Construction 3(45), 4-12 (2017)

6. B. Cullingworth, R.W. Caves, Planning in the USA: Policies, Issues, and Processes. 4th Edition (Routledge, London and New York, 2014)

7. R. Kitchin, The Data Revolution. Big Data, Open Data, Data Infrastructures and Their Consequences (SAGE Publications Ltd., Londres, 2014)

8. BRICS Business Magazine. Cities Getting Smart http://bricsmagazine.com/en/articles/cities-getting-smart.

9. Social-political net of regions "Regions online". Russian cities' happiness (2015) indexhttp://www.gosrf.ru/news/5927/

10. The recommendations about preparation of National reports of the states of the region (CIS countries) to Conference of the UNO on housing and a sustainable development Habitat III 9(961), 12-13 (2014)

11. L. Gokhberg, Russian Regional Innovation Development Rating (HSE, Moscow, 2015).

12. Engineering systems. Design Smart building. Smart quarter. Smart city (2018) http://www.myshared.ru/slide /902728/

13. E. Nezhnikova, A. Papelniuk, A. Gorokhova, International Journal of Energy Economics and Policy 8(1), 203-211 (2018)

14. L. Hollis, Cities Are Good for You. The Genius of the Metropolis (Strelka Press, Moscow, 2015)

15. A.V. Panfilov, Smart City. City formation within the technological concept (Samara State Technical University, Samara, 2017) 